\title{
Research on Meteorological Information Transmission Mechanism in the Age of All Media
}

\author{
Ling Lin, Bufen Shao, Huihui Zhang, Xinmei Li* \\ Fuzhou Meteorological Bureau, Fuzhou, China \\ Email:`261993273@qq.com
}

How to cite this paper: Lin, L., Shao, B.F., Zhang, H.H. and Li, X.M. (2018) Research on Meteorological Information Transmission Mechanism in the Age of All Media. Journal of Geoscience and Environment Protection, 6, 60-65.

https://doi.org/10.4236/gep.2018.68006

Received: July 9, 2018

Accepted: August 18, 2018

Published: August 21, 2018

Copyright $\odot 2018$ by authors and Scientific Research Publishing Inc. This work is licensed under the Creative Commons Attribution International License (CC BY 4.0).

http://creativecommons.org/licenses/by/4.0/

\begin{abstract}
This paper takes the Fujian Meteorological Service Center as the research objective, and uses the methods of departmental data sharing and network search to study the dissemination mechanism of meteorological information in the whole media era. The result shows that it is of great significance to actively adapt to the characteristics of information dissemination in the all-media era, establish and improve meteorological information service rules and supervision mechanisms, actively explore strong measures to strengthen the monitoring of meteorological services, promptly release authoritative voices, curb the breeding of rumors, regulate the propagation path, and conduct meteorological information dissemination assessment. Finally, this paper proposes the construction of meteorological information dissemination mechanism from five aspects: service quality assessment, introduction of enterprise information filing and credit management system, establishment of authoritative meteorological information sharing channels, formulation of emergency response plans, and vigorous promotion of meteorological popularization. The mechanism provides a theoretical reference for the meteorological department to better adapt to the all-media context and to carry out scientific and effective media-based public opinion information risk management.
\end{abstract}

\section{Keywords}

All Media, Meteorological Information Dissemination

\section{Introduction}

At present, China has entered a new era of mediaization from the media, institutional media, platform media and other media integrations, and the whole media 
communication has become the main form of information dissemination. All media means that information dissemination uses a variety of media expressions such as text, pictures, and images, and uses a variety of media formats such as newspapers, radio, television, and the Internet to carry out converged communication to achieve wide coverage, full-time space, and multi-terminal information fusion reception. Real-time interaction, open sharing, media for everyone, media everywhere, anyone can get any information they want from any terminal at any time and place, which is a prominent feature of all-media communication. These characteristics make media communication shape people's thinking characteristics and behaviors with its powerful influence. The social life, social relations, social governance model and other social life are highly mediated. In this social context of full media, full time and space penetration, this paper aims to enhance the meteorological department's risk management of sudden public opinion information under the new situation [1].

\section{Research Objective and Method}

\subsection{Research Objective}

Fujian Meteorological Service Center is the only and most authoritative professional meteorological information release and professional meteorological service agency in Fujian Province. It undertakes provincial-level professional weather forecasting, film and television weather program production, information network meteorological service, climate application service, and meteorological environment assessment, industry meteorological application collaborative research, professional meteorological data analysis tasks and historical meteorological data applications.

Nowadays, with the rapid development of new media technologies and information technology, the meteorological information service industry is booming and growing rapidly. However, the sources of meteorological information are unknown, the dissemination is not timely and accurate, and the lack of illegality and release of stations and time still appear from time to time. The diversity and convenience of meteorological information dissemination channels have quickly spread the many "meteorological rumors" that catch people's attention [2]. Take Fuzhou as an example. In July 2017, "Fuzhou became the new four stoves" and the rumors of "the hottest summer in Fuzhou history" spread everywhere in September 2017. At the end of April 2018, the news of "30 consecutive days of rain in Fuzhou" was flooding in the circle of friends. In mid-May 2018, the unofficial weather APP forecasted temperatures as high as $40^{\circ} \mathrm{C}$, while the meteorological department predicted a maximum temperature of only $37^{\circ} \mathrm{C}$, and the live maximum temperature did not exceed $37^{\circ} \mathrm{C}$. At the beginning of June 2018, the typhoon came, the unreasonable news that may affect Fuzhou during the college entrance examination and the heavy rain in Fuzhou next week was rumored in major media, etc. 


\subsection{Research Method}

In recent years, in the context of global climate change, on the one hand, the frequency of extreme meteorological disasters has increased. On the other hand, the demand for meteorological disaster prevention and mitigation in the whole society is getting higher and higher, which has caused great pressure on the guidance of the meteorological department. The public opinion incident involving the meteorological department has occurred [3]. To fully understand the current status of meteorological information dissemination in the era, this paper adopted methods including departmental information sharing, service channel back-checking, network search, and filing public information inquiry.

\section{Research Result}

In recent years, the meteorological department has actively opened up the meteorological service market, and the information dissemination channels have been increasing, and the meteorological services have become more convenient and more individual. Accompanied by the "non-mainstream" information is very easy to breed, wrong to guide the public. The laws and regulations such as the Meteorological Law, the Measures for the Administration of the Release and Dissemination of Meteorological Forecasts, and the Measures for the Administration of Meteorological Information Services clearly stipulate that "the State shall implement a unified release system for public weather forecasts and severe weather warnings". "For media and units to disseminate weather forecasts, the latest weather forecast provided by the meteorological observatory to which the local meteorological authority belongs shall be used, and the name and release time of the meteorological observatory issued by the weather forecast shall be indicated, and the content and conclusion of the weather forecast shall not be changed by itself." However, a series of problems such as inaccurate forecasting elements, incomplete forecasting content, irregular warning information, untimely information dissemination, and unclear source time are common problems of unofficial meteorological information. As far as meteorological information services are concerned, if the supervision fails to keep up, the distortion effect of "bad money expelling good money" will be magnified, which will seriously restrict the development of honest and trustworthy operators and new market entities. In addition to the all-media era, real-time interaction, open sharing, everyone's media, media everywhere, and media's information dissemination characteristics make the speed of lyrics spread faster, control and guidance are more difficult, and the impact cannot be underestimated. Effective control of the authenticity, accuracy and timeliness of network public opinion information plays a vital role in regulating network information, and will also have a certain impact on the stability of social order [3]. Therefore, it is of great significance to actively explore effective measures to strengthen the monitoring of meteorological services, timely release of authoritative voices, curb the breeding of rumors, standardize the path of communication, and carry out assessment 
of meteorological information dissemination.

\section{Conclusions and Discussion}

Therefore, effectively preventing and scientifically coping with the meteorological emergencies in the new media environment, reducing the impact and guiding public opinion are a task that the meteorological department needs to solve urgently [4]. In order to promote the healthy development of the meteorological information service industry in accordance with the law, it is necessary to establish and improve the rules and supervision mechanisms for meteorological information services.

\subsection{Jointly Issued a Communication Management Approach to Conduct Service Quality Assessment}

A working mechanism for Internet enterprise information sharing, joint meetings, information release, and joint law enforcement with the local network office is established to form a joint market management of meteorological information services. The "Measures for the Administration and Publication of Public Weather Forecasts" was issued to provide a code of conduct for meteorological information service units, so that market supervision can be based on laws. A monitoring and evaluation system for meteorological information dissemination quality is established, and the quality of meteorological information disseminated and the speed of early warning update of meteorological information service units on websites, mobile APPs, newspapers, mobile phone text messages, TV programs, new media and other channels are monitored [5]. The quality assessment results are published in a prominent position on a regular basis through local authoritative media. For illegal activities and major public opinion incidents, measures such as substantive interviews, punishments, deletion of messages or stoppages will be taken.

\subsection{Jointly Issued Enterprise Information Filing and Credit Management System}

The local industrial and commercial department and the credit management department are cooperated to issue the Meteorological Information Service Unit Record Management System and Credit Management System. After submitting the application, the meteorological information service unit can enter the ranks of meteorological information services and enjoy the right to share the authoritative meteorological data. And it was announced to the public as an authoritative channel for the release of meteorological information, and entered the government credit management monitoring system. The meteorological department and the relevant departments and credit management departments realized information sharing, carried out joint credit punishment, established a work coordination mechanism, and incorporated all meteorological administrative licenses, administrative penalties, and service unit filing information into the en- 
terprise credit information publicity system.

\subsection{Establish a Rapid Sharing Channel for Authoritative Weather Information}

A meteorological information sharing platform is built to provide data interfaces to provide timely information on weather conditions, weather forecasts for the next three days, and effective warning signals issued by local meteorological stations [6] (Figure 1). The authority and timeliness of media dissemination of meteorological information are improved. The warning information through train to the meteorological information service unit on the white list is open, and the media is encouraged to regulate the dissemination of meteorological warning information.

\subsection{Formulate Emergency Response Plans for Emergencies}

Establish a public opinion emergency leadership team, formulate a clear work plan, and determine the work responsibilities of relevant departments. Establish an emergency warning mechanism for emergencies, pay attention to the whole process, feedback from the normal state, scientific pre-judgment, and regularly search and analyze the information related to the unit, so as to plan ahead and discover the signs in advance. Establish an emergency information release and tracking mechanism, standardize the release of information, strengthen the tracking of information after the release of information and follow-up of public opinion events, respond to the first time of the public opinion incident, clarify the falsehood that triggered the public opinion, and stabilize public sentiment. Establish a network spokesperson system and a media-wide public opinion

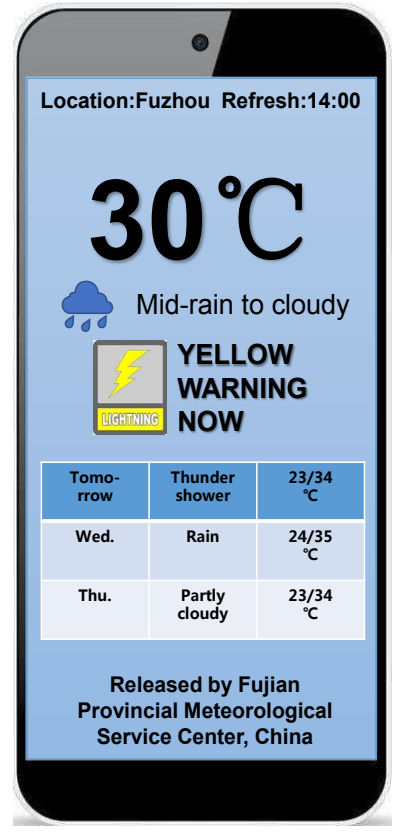

Figure 1. Meteorological information sharing platform. 
guidance work mechanism, set up a network spokesperson, timely use government microblogs, WeChat to communicate with the public, unblock public opinion, formulate public opinion guidance work plans and rumors, and establish credibility [4].

\subsection{Actively Build a Platform and Vigorously Carry out the Promotion of Meteorological Law}

Joint local propaganda department and network information office vigorously carried out the popularization of meteorological law, invited news communication Internet companies, meteorological information disseminators and enthusiasts and the public to participate in, and guide social media and the public to obtain weather forecast and warning information from formal channels. It is necessary to disseminate meteorological information in a reasonable and legal manner so that meteorological information "sources should be legal, publication should be timely, sources should be marked, and units must be filed". At the same time, actively build a platform for communication and exchange between meteorological departments and meteorological information service units, conduct scientific popularization of common meteorological terms, and guide the healthy development of meteorological information service industry.

\section{Funding}

This work was supported by Soft Science Research Project of Fujian Meteorological Bureau (No.1804).

\section{Conflicts of Interest}

The authors declare no conflicts of interest regarding the publication of this paper.

\section{References}

[1] Xia, Y.X., Lan, Y.X. and Zeng, R.X. (2016) Research on Risk Management Model of Sudden Events in All-Media Context. Books and Information, 3, 11-18.

[2] Lu, W., Guo, T. and Mai, W.Q. (2017) Method and Statistical Analysis of the Meteorological Information Service Units in Guangdong Province. Guangdong Meteorology, 2, 62-65.

[3] Wang, X.W., Xing, Y.F. and Zhao, D. (2015) Research on Network and Emotional Information Communication in the Environment of Hijacking Based on Social Network Analysis. Library and Information Work, 59, 14-21.

[4] Yan, Z.N., Yang, C.H. and Qiu, Y.Y. (2017) Analysis on the Development of Qinghai Meteorological Service in the New Media Era. Qinghai Science and Technology, 4, 74-76.

[5] Liu, A.R. (2007) Meteorological Information Sharing Platform Development Skill. Meteorlolgical and Environmental Sciences, z1, 201-202.

[6] Wang, S.G., Zheng, L. and Zhu, J.J. (2016) Research on the Emergency Response Mechanism of Meteorological Emergencies in the New Media Environment. Journalism Research Guide, 7, 65-67. 